\title{
Mixed Convection MHD Stagnation Point Flow over a Stretching Surface with the Effects of Heat Source or Sink and Viscous Dissipation
}

\author{
Kankanala Sharada, Bandari Shankar \\ Department of Mathematics, Osmania University, Hyderabad, India \\ Email: sharada.kankan@yahoo.com
}

Received 20 November 2015; accepted 28 March 2016; published 31 March 2016

Copyright (C) 2016 by authors and Scientific Research Publishing Inc.

This work is licensed under the Creative Commons Attribution International License (CC BY). http://creativecommons.org/licenses/by/4.0/

\section{(c) (i) Open Access}

\begin{abstract}
The present study deals with MHD mixed convection stagnation point flow over a stretching sheet with the effects of heat source/sink and viscous dissipation including convective boundary conditions. The governing partial differential equations are transformed into ordinary differential equations by applying similarity transformations. These equations are then solved numerically by using finite difference scheme known as the Keller Box method. The effects of various parameters on velocity and temperature profiles are presented graphically interpreted and the results are discussed.
\end{abstract}

\section{Keywords}

Magnetohydrodynamics (MHD), Mixed Convection, Stagnation Point, Heat Source, Viscous Dissipation

\section{Introduction}

The study of MHD, boundary layer flow with heat transfer from a stretching sheet has several applications in many industrial fields. Magnetic fields can be used to manage thermal energy in flowing electrically conducting polymers (Garnier [1]). Crane [2] first investigated the flow of an incompressible fluid over a linearly stretching sheet. Boundary layer flow behaviour on continuous solid surface moving at a constant speed is investigated by Sakiadas [3]. Chakrabarthi and Gupta [4] discussed heat transfer of hydromagnetic flow over a stretching sheet. Heat transfer over a continuous, stretching surface with suction/blowing is investigated by Chen and Char [5]. T. 
C. Chiam [6] explained heat transfer in a two-dimensional fluid over a linearly stretching sheet in the presence of suction/blowing and with variable thermal conductivity.

In fluid dynamics, the stagnation point flow and flow over a stretching surface are important in theoretical and applications point of view. In fluid dynamics, stagnation is a point in a flow field where the local velocity of the fluid is zero. Stagnation points exist at the surface of objects in the flow field, where the fluid is brought to rest by the object. Stagnation flow towards a stretching sheet is investigated by Wang [7]. Mixed convection MHD stagnation point flow on vertical, linearly stretching sheet is explained by Ishak [8]-[10]. The steady two-dimensional stagnation point flow on a stretching sheet was first discussed by Chaim [11]. Stagnation point flow over a stretching surface is explained by T. R. Mahapatra and A. S. Gupta [12]. Recently Bhattacharya [13] investigated heat transfer in boundary layer stagnation point flow over a stretching sheet. In many electronic applications, temperature becomes an important role when designing a system. We have practical applications for various heat source/sink arrangements. An effect of heat source/sink on MHD flow over a shrinking sheet is explained by Krishnendu Bhattacharyya [14]. F. M. Hady [15] described the effects of heat source/sink on MHD viscoelastic fluid over a non linear stretching sheet. Mahapatra, T. R. and A. S. Gupta [16] discussed heat transfer in stagnation point flow over a stretching sheet. The effects of viscous dissipation and internal heat generation of a viscous fluid on a stretching sheet are investigated by Vajravelu K. and Hadjinicolaou A. [17]. Sharma P. R. and Singh G. [18] described the effects of viscous dissipation and heat source/sink on MHD stagnation point flow over a linearly stretching sheet.

This paper provides the solution to the problem of fluid flow, heat transfer of mixed convection MHD stagnation point flow over a stretching surface by considering the effects of heat source/sink and viscous dissipation including convective boundary conditions by adopting the Keller box method.

\section{Mathematical Formulation}

Consider two-dimensional steady, incompressible MHD stagnation point flow of a viscous fluid over a stretching sheet with convective boundary condition. It is assumed that the stretching velocity $u_{w}(x)$ and the external velocity $U(x)$ are of the forms $u_{w}(x)=b x, U(x)=a x$ respectively, where $a, b$ are constants. A magnetic field of uniform strength $B$ is applied perpendicular to the surface in the $y$ direction, which generates magnetic field in the $x$ direction. A heat source/sink is located within the flow to allow for certain heat generation or absorption effects.

Considering $u, v$ as velocity components in the directions of $x$ and $y$ respectively in the flow field. The governing equations of continuity, momentum, energy and concentration are given by

$$
\begin{gathered}
\frac{\partial u}{\partial x}+\frac{\partial v}{\partial y}=0 \\
u \frac{\partial u}{\partial x}+v \frac{\partial u}{\partial y}=U \frac{\mathrm{d} U}{\mathrm{~d} x}+v \frac{\partial^{2} u}{\partial y^{2}}+g \beta_{T}\left(T-T_{\infty}\right)-\frac{\sigma B^{2}}{\rho}(u-U) \\
u \frac{\partial T}{\partial x}+v \frac{\partial T}{\partial y}=\alpha \frac{\partial^{2} T}{\partial y^{2}}+Q\left(T-T_{\infty}\right)+\frac{\mu}{\rho C_{p}}\left(\frac{\partial u}{\partial y}\right)^{2}
\end{gathered}
$$

where $\rho$ is the density of the fluid, $\sigma$ is the electrical conductivity, $v$ is the kinematic viscosity, $B$ is the magnetic induction, $\alpha\left(=\frac{K}{\rho C_{p}}\right)$ is the thermal diffusivity, $K$ is the thermal conductivity, $\mu$ is the dynamic co-efficient of viscosity, $C_{p}$ is the specific heat capacity at constant pressure, $T_{\infty}$ is the free stream temperature, $Q$ is the volumetric rate of heat source or sink diffusion ratio. The boundary conditions considered are defined as

$$
\begin{gathered}
u=u_{w}(x)=b x, v=0,-K \frac{\partial T}{\partial y}(x, 0)=h_{f}\left(T_{f}-T(x, 0)\right) \text { at } y=0 . \\
u=U(x), T \rightarrow T_{\infty} \text { as } y \rightarrow \infty
\end{gathered}
$$

where $T_{f}$ is the temperature of fluid, $h_{f}$ is the heat transfer coefficient. 
Introducing the similarity transformations

$$
\eta=\sqrt{\frac{U}{v x}} y, \psi(x)=\sqrt{v x U} f^{\prime}(\eta), \quad \theta(\eta)=\frac{T-T_{\infty}}{T_{W}-T_{\infty}},
$$

$u=a x f^{\prime}(\eta), \quad v=-\sqrt{a v}\left[f(\eta)-\eta f^{\prime}(\eta)\right]$ into the Equations (2) \& (3) we get

$$
\begin{gathered}
f^{\prime \prime \prime}+f f^{\prime \prime}-\left(f^{\prime}\right)^{2}-M\left(f^{\prime}-1\right)+\lambda \theta+1=0, \\
\frac{1}{P r} \theta^{\prime \prime}+f \theta^{\prime}+S \theta+E c\left(f^{\prime \prime}\right)^{2}=0
\end{gathered}
$$

where $M=\frac{\sigma B_{0}^{2}}{\rho a}$ is the magnetic parameter, $\operatorname{Pr}=\frac{v}{\alpha}$ is the Prandtl number, $\lambda=\frac{G r}{\operatorname{Re}^{2}}$ is the mixed convection parameter, $R e=\frac{U x}{v}$ is the Reynolds number, $G r=\frac{g \beta_{T}\left(T-T_{\infty}\right) x^{3}}{v^{2}}$ is the Grashoff number, $E c=\frac{a^{2}}{C_{p}\left(T_{f}-T_{\infty}\right)}$ is the Eckert number, $S=\frac{Q}{a}$ is the heat generation parameter.

The boundary conditions are reduced to

$$
\begin{gathered}
\eta=0: \quad f(0)=0, \quad f^{\prime}(0)=\epsilon, \quad \theta^{\prime}(0)=-\gamma(1-\theta(0)) . \\
\eta \rightarrow \infty: \quad f^{\prime}(\infty)=1, \quad \theta(\infty)=0
\end{gathered}
$$

where $\epsilon=\left(\frac{b}{a}\right) \geq 0$ is the stretching parameter and $\gamma=\left\{\frac{h_{f}}{K}\left(\sqrt{\frac{v}{a}}\right)\right\}$ is the conjugate parameter for the convective boundary condition. The skin friction coefficient at the surface of the sheet is given by $C_{f}=\frac{2 \tau_{w}}{\rho U^{2}}$ $\left[C_{f} R e^{1 / 2}=-f^{\prime \prime}(0)\right]$, where $\tau_{w}=-\mu\left(\frac{\partial u}{\partial y}\right)_{y=0}$ is the shear stress, $N u_{x}=\frac{x q_{w}}{k\left(T_{w}-T_{\infty}\right)} \quad\left[N u_{x}=-R e^{1 / 2} \theta^{\prime}(0)\right]$ is the Nusselt number, where $q_{w}=-K\left(\frac{\partial T}{\partial y}\right)_{y=0}$ is the rate of heat transfer.

\section{Method of Solution}

The governing equations with boundary equations are solved numerically by using finite difference scheme known as Keller box method which is described by Cebeci and Bradshaw [19]. This method involves the following steps.

Step 1: Reducing higher order ODEs (systems of ODES) in to systems of first order ODEs.

Step 2: Writing the systems of first order ODEs into difference equations using central difference scheme.

Step 3: Linearizing the difference equations using Newton's method and writing it in Vector form.

Step 4: Solving the system of equations using block elimination method.

\section{Numerical Discussions}

In this process the step size $\Delta \eta=0.01$ is used to obtain numerical solution. Table 1 shows that the comparison between the present results with the previously described results by Wang, Yacob and Ishak for various values of the stretching parameter $\epsilon$. It has been found that they are in good agreement.

\section{Results and Discussion}

In this study, the following values are used for the numerical computations $M=0.05, S=0.5, \lambda=0.1$, 
$\operatorname{Pr}=0.72, \gamma=0.1, \epsilon=2.0, E c=0.1$. These values are mentioned throughout the computations unless otherwise stated.

Figure 1 illustrates the velocity profile for different values of the magnetic parameter $M$. As The value of $M$ increases, velocity decreases due to Lorentz force. Figure 2 shows that the velocity profile for different values of mixed convection parameter $\lambda$. It illustrates that the dimensionless velocity increases, as the value of $\lambda$ increases. As $\lambda$ increases, the buoyancy effects increase and hence the fluid flow accelerates (Table 2).

Figure 3 depicts the effects of $\epsilon$ on dimensionless velocity profiles, which produce $f^{\prime}(0)=\epsilon$ and $f^{\prime}(\infty)=1$. When $\epsilon>1$, the flow has an inverted boundary layer structure and the thickness of the boundary layer decreases with $\epsilon$. On the other hand, when $\epsilon<1$, the flow has a boundary layer structure, which results from the fact that when $\frac{b}{a}<1$, the external velocity ax of the surface exceeds the velocity bx of the stretching

Table 1. Comparison of results for $-f^{\prime \prime}(0)$ with previous published data.

\begin{tabular}{cccc}
\hline$\epsilon$ & Yacob and Ishak [20] & Wang [8] & Present \\
\hline 0.0 & 1.23258 & 1.23258 & 1.2326 \\
0.5 & 0.71329 & 0.71329 & 0.7133 \\
2.0 & -1.88730 & -1.88730 & -1.8873 \\
\hline
\end{tabular}

Table 2. Effects of skin friction, heat and mass transfer coefficients for various values of $\epsilon, \gamma, \lambda, E c, S$.

\begin{tabular}{ccccccc}
\hline$\Gamma$ & $\epsilon$ & $\Lambda$ & $E c$ & $S$ & $-f^{\prime \prime}(0)$ & $-\theta^{\prime}(0)$ \\
\hline 1.0 & 2.0 & 0.1 & 0.1 & 0.5 & 1.8814 & 0.2285 \\
1.0 & 3.0 & 0.1 & 0.1 & 0.5 & 4.2831 & 0.0764 \\
1.5 & 2.0 & 0.1 & 0.1 & 0.5 & 1.8775 & 0.2875 \\
2.5 & 2.0 & 0.1 & 0.1 & 0.5 & 1.8730 & 0.3550 \\
1.0 & 2.0 & 1.0 & 0.1 & 0.5 & 1.7030 & 0.2429 \\
1.0 & 2.0 & 3.0 & 0.1 & 0.5 & 1.3216 & 0.2695 \\
1.0 & 2.0 & 0.1 & 1.5 & 0.5 & 1.8747 & 0.6733 \\
1.0 & 2.0 & 0.1 & 2.0 & 0.5 & 1.8723 & 0.9924 \\
1.0 & 2.0 & 0.1 & 0.1 & 0.0 & 1.8830 & 0.3475 \\
1.0 & 2.0 & 0.1 & 0.1 & 1.0 & 1.8789 & 0.0674 \\
\hline
\end{tabular}

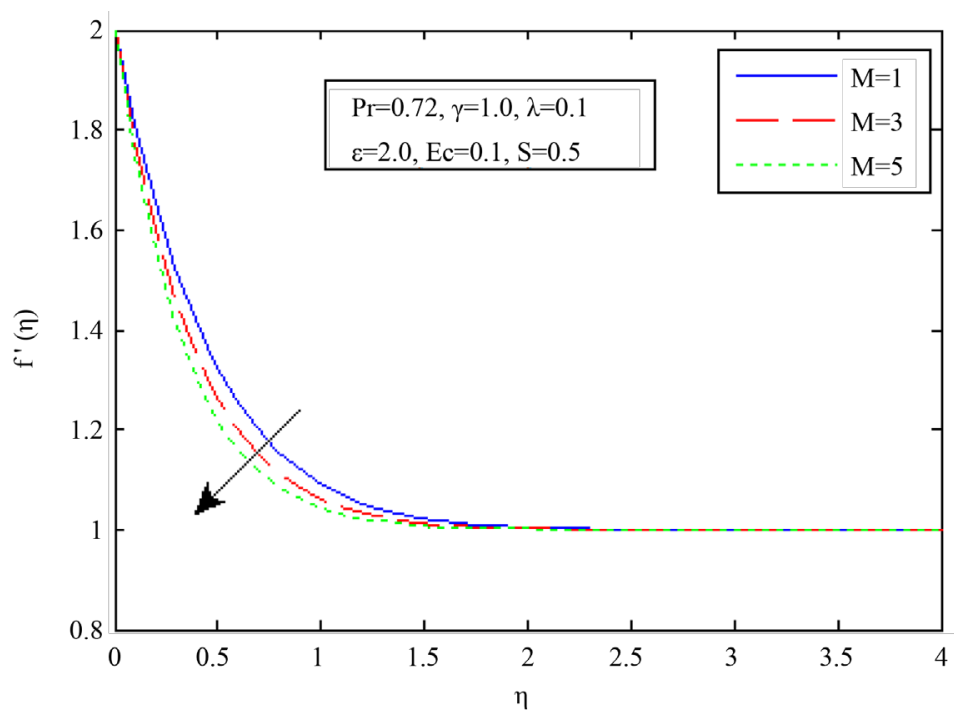

Figure 1. Velocity profile for various values of $M$. 


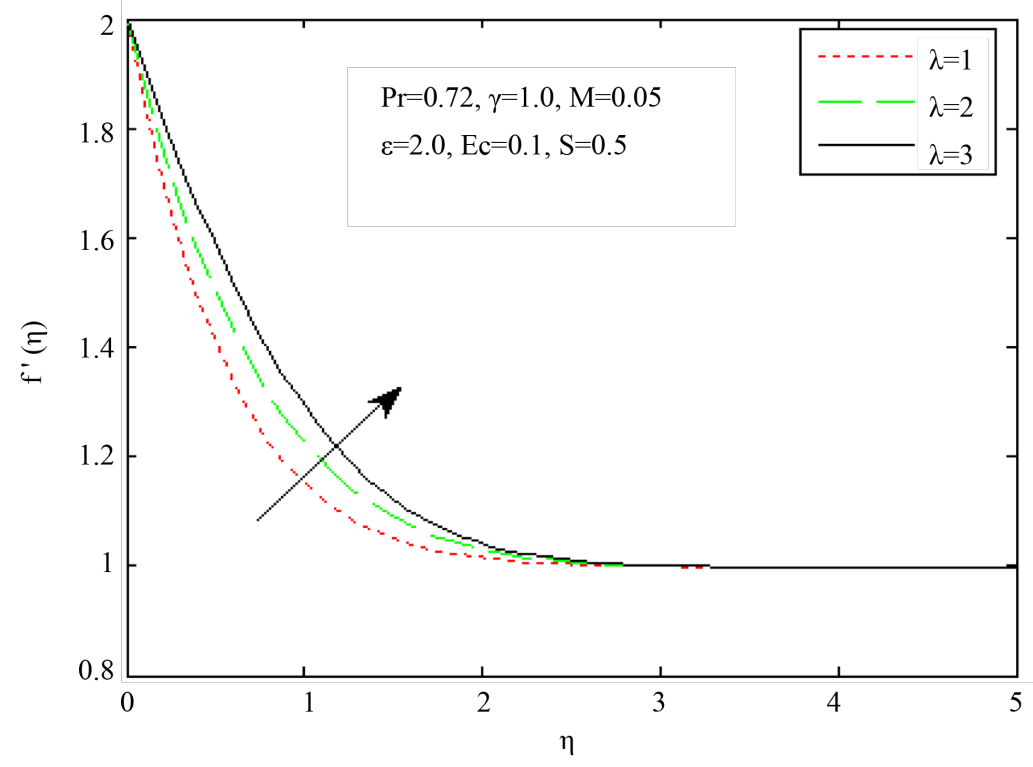

Figure 2. Velocity profile for various values of $\lambda$.

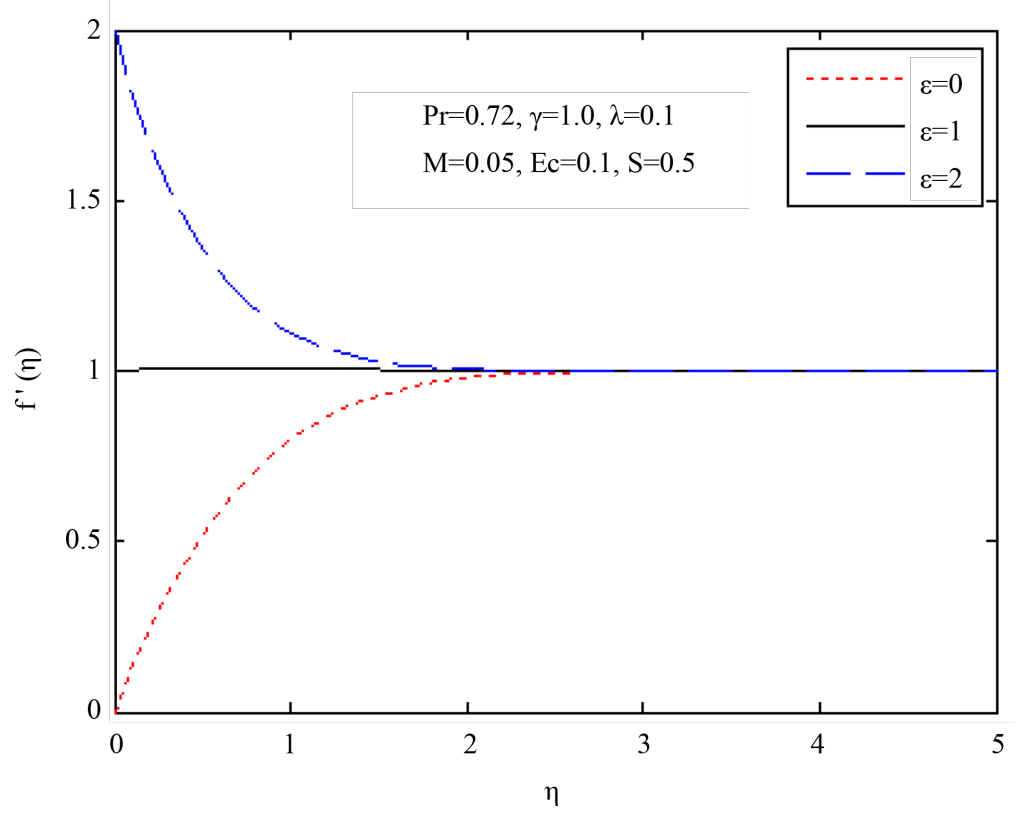

Figure 3. Velocity profile for various values of $\epsilon$.

sheet. For this case, the boundary layer thickness increases with the increase of $\epsilon$. Figure 4 shows that the temperature profile for the values of $\epsilon$. The temperature is found to decrease with the increasing values of $\epsilon$.

Figure 5 shows that effect of heat source parameter $S$ on temperature profile. It generates heat in the fluid. Therefore temperature profile increases. Figure 6 indicates the temperature profile for different values of conjugate parameter $\gamma$. The effects of Prandtl number on temperature profiles are shown in Figure 7. Prandtl number can be used to increase the rate of cooling conducting fluids. Prandtl number signifies the ratio of momentum diffusivity to thermal diffusivity.

Increasing the values of the $E c$ generates heat in the fluid due to frictional heating. Figure 8 demonstrates that influence of the $E c$ on the profile of temperature. It is observed that the temperature profile increases as the value of the $E c$ increases. 


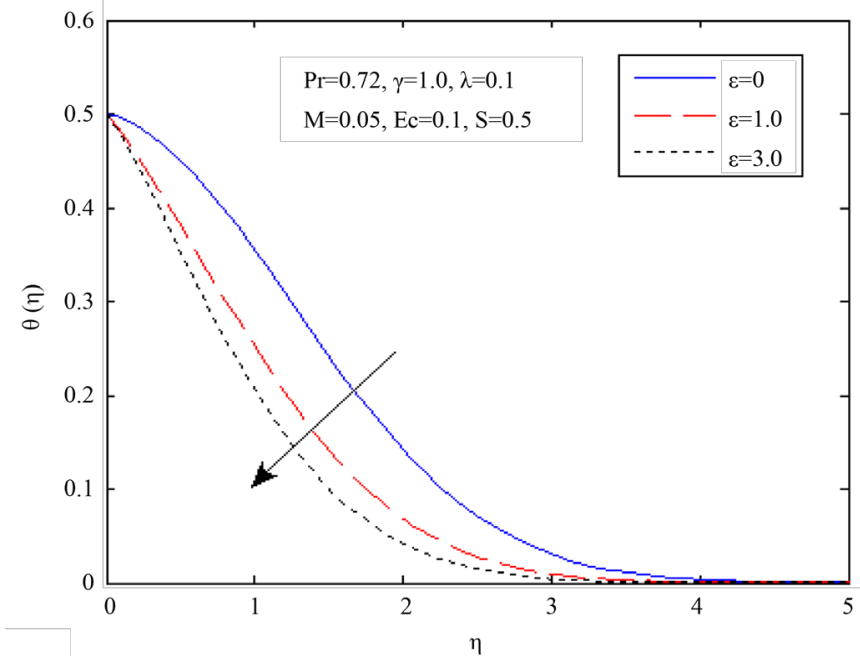

Figure 4. Temperature profile for various values of $\varepsilon$.

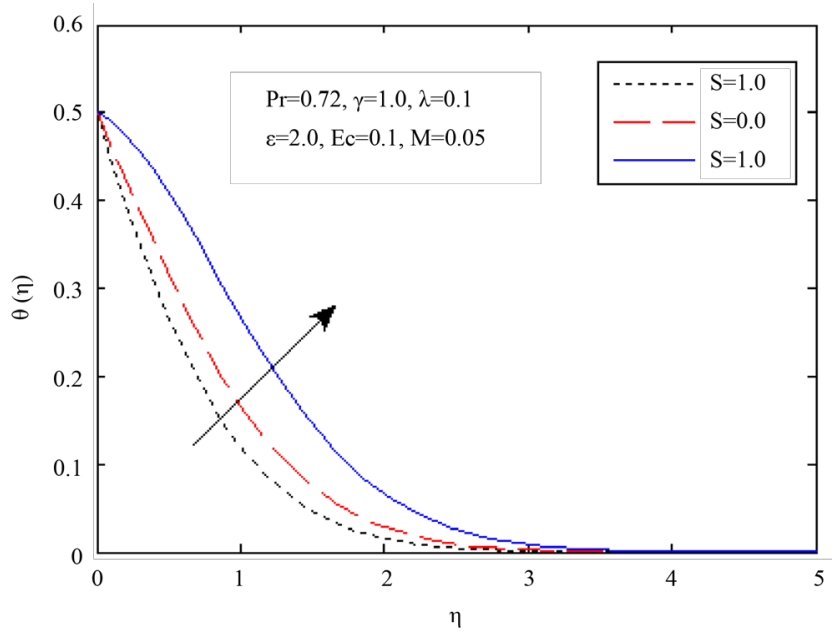

Figure 5. Temperature profile for various values of $S$.

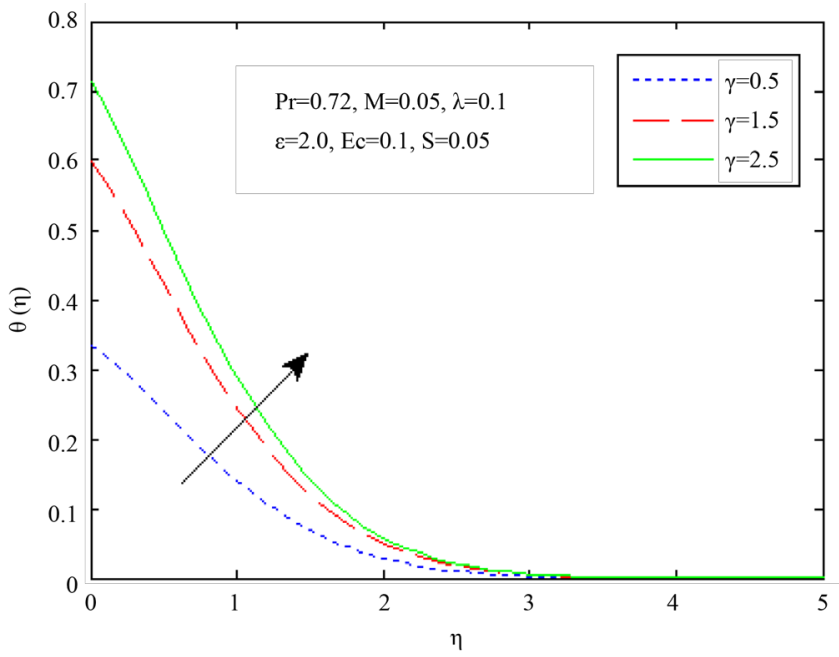

Figure 6. Temperature profile for various values of $\gamma$. 


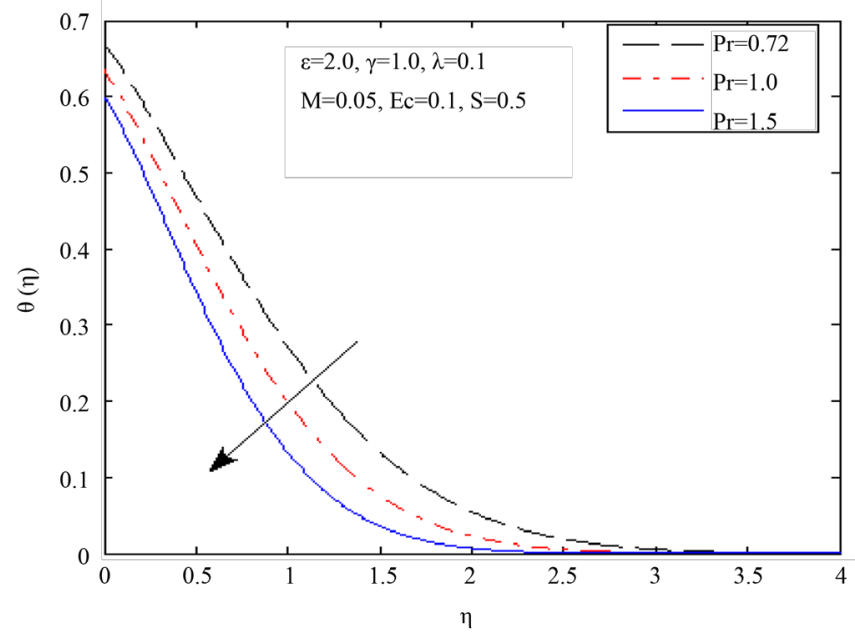

Figure 7. Temperature profile for various values of $\mathrm{Pr}$.

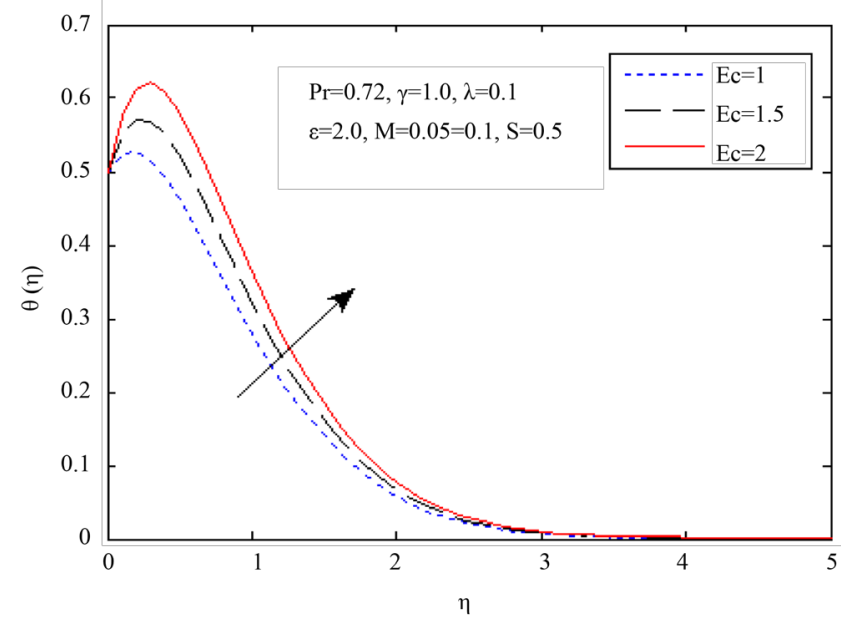

Figure 8. Temperature profile for various values of $E c$.

\section{Conclusions}

The numerical solutions for mixed convection MHD stagnation point flow over a stretching surface with the effects of various parameters were analyzed. The effects of various parameters on heat flow characteristics were also discussed. From the graphical representations, we have the following observations.

- The velocity increases with increasing values of the magnetic parameter $M$.

- An increase in the mixed convection parameter $\lambda$ increases the velocity profiles.

- An increase in the value of $\epsilon$ reduces the temperature, and increases the velocity profiles.

- With increasing values of conjugate parameter $\gamma$ the temperature profile increases.

- An increase in the Eckert number $E c$ increases the temperature profile.

\section{References}

[1] Garnier, M. (1962) Magneto Hydrodynamics in Materials Processing. Philosophical Transactions of the Royal Society of London Series A-Mathematical Physical and Engineering Sciences, 344, 249-263. http://dx.doi.org/10.1098/rsta.1993.0090

[2] Crane, L.J. (1970) Flow past a Stretching Plate. ZAMP, 21, 590-595. http://dx.doi.org/10.1007/BF01587695

[3] Sakiadas, B.C. (1961) Boundary-Layer Behavior on Continuous Solid Surfaces. AIChE Journal, 7, 26-28. http://dx.doi.org/10.1002/aic.690070108 
[4] Chakrabarti, A. and Gupta, A.S. (1979) Hydromagnetic Flow and Heat Transfer over a Stretching Sheet. Quarterly of Applied Mathematics, 37, 73-78.

[5] Chen, C.K. and Char, M. (1988) Heat Transfer on a Continuous, Stretching Surface with Suction and Blowing. Journal of Mathematical Analysis and Applications, 135, 568-580. http://dx.doi.org/10.1016/0022-247X(88)90172-2

[6] Chiam, T.C. (1998) Heat Transfer in a Fluid with Variable Thermal Conductivity over a Linearly Stretching Sheet. Acta Mechanica, 129, 63-72. http://dx.doi.org/10.1007/BF01379650

[7] Wang, C.Y. (2008) Stagnation Flow towards a Shrinking Sheet. International Journal of Non-Linear Mechanics, 43, 377-382. http://dx.doi.org/10.1016/j.ijnonlinmec.2007.12.021

[8] Ishak, A., Nazar, R. and Pop, I. (2007) Mixed Convection on the Stagnation Point Flow toward a Vertical, Continuously Stretching Sheet. Journal of Heat Transfer, 129, 1087-1090. http://dx.doi.org/10.1115/1.2737482

[9] Ishak, A., Nazar, R. and Pop, I. (2008) Post Stagnation Point Boundary Layer Flow and Mixed Convection Heat Transfer over a Vertical, Linearly Stretching Sheet. Archives of Mechanics, 60, 303-322.

[10] Ishak, A., Jafar, K., Nazar, R. and Pop, I. (2009) MHD Stagnation Point Flow towards a Stretching Sheet. Physica A: Statistical Mechanics and its Applications, 388, 3377-3383. http://dx.doi.org/10.1016/j.physa.2009.05.026

[11] Chiam, T.C. (1998) Heat Transfer in a Fluid with Variable Thermal Conductivity over a Linearly Stretching Sheet. Acta Mechanica, 129, 63-72. http://dx.doi.org/10.1007/BF01379650

[12] Mahapatra, T.R. and Gupta, A.S. (2003) Stagnation Point Flow towards a Stretching Surface. Canadian Journal of Chemical Engineering, 81, 258-263. http://dx.doi.org/10.1002/cjce.5450810210

[13] Bhattacharyya, K. (2013) Heat Transfer in Boundary Layer Stagnation Point Flow over a Stretching Sheet. Chinese Physics B, 22.

[14] Bhattacharyya, K. (2011) Effects of Heat Source/Sink on MHD Flow and Heat Transfer over a Shrinking Sheet with Mass Section. Chemical Engineering Research Bulletin, 15, 12-17. http://dx.doi.org/10.3329/cerb.v15i1.6524

[15] Hady, F.M., Mohamed, R.A. and Elshehabey, H.M. (2013) Thermal Radiation, Heat Source/Sink and Work Done by Deformation Impacts on MHD Viscoelastic Fluid over a Non Linear Stretching Sheet. WJM, 13, 203-214. http://dx.doi.org/10.4236/wjm.2013.34020

[16] Mahapatra, T.R. and Gupta, A.S. (2002) Heat Transfer in Stagnation-Point Flow towards a Stretching Sheet. Heat and Mass Transfer, 38, 517-521. http://dx.doi.org/10.1007/s002310100215

[17] Vajravelu, K. and Hadjinicolaou, A. (1993) Heat Transfer in a Viscous Fluid over a Stretching Sheet with Viscous Dissipation and Internal Heat Generation. International Communications in Heat and Mass Transfer, 20, 417-430. http://dx.doi.org/10.1016/0735-1933(93)90026-R

[18] Sharma, P.R. and Singh, G. (2008) Effect of Viscous Dissipation and Heat Source/Sink in Steady MHD Flow near a Stagnation Point on Linearly Stretching Sheet Subject to Different Thermal Boundary Conditions. ASME Journal of France, 77, 35-53.

[19] Cebeci, T. and Bradshaw, P. (1984) Physical and Computational Aspects of Convective Heat Transfer. Springer, Berlin. http://dx.doi.org/10.1007/978-3-662-02411-9

[20] Yacob, N.A. and Ishak, A. (2012) Stagnation Point Flow towards a Stretching/Shrinking Sheet in a Micro Polar Fluid with a Convective Surface Boundary Condition. Canadian Journal of Chemical Engineering, 90, 621-626. http://dx.doi.org/10.1002/cjce.20517 